\title{
Bajo la pluma de la nación. La narrativa homogeneizante de la historiografía liberal sobre la sociedad chilena hacia 1810*
}

Javier Sadarangani Leiva**

Recibido: junio de 2014 Aprobado: septiembre de 2014

Ustedes los historiadores son quienes más han modificado la historia', se nos dice con frecuencia a los que nos dedicamos a esta disciplina del saber humano. Tal afirmación nos llena de orgullo [...] Pero ¿̇no será más bien una burla? [...] En vez de elogiarnos ¿no nos estarán tachando de falsificadores? Juan Brom, 2003.

Resumen: El discurso homogeneizante que notamos entre los miembros de la sociedad chilena no nace de manera espontánea ni tampoco resulta fortuito, sino que es resultado de una tradición historiográfica que se propagó y se instaló en el sentido común de muchos, el cual entendió y describió a nuestra sociedad de manera uniforme, especialmente hacia 1810. Así, el propósito de este trabajo es dar cuenta, a través de un análisis bibliográfico, cómo y por qué la historiografía liberal -

* Quiero agradecer a Matías Marambio de la Fuente por sus observaciones y comentarios al texto preliminar, los cuales me fueron útiles y esclarecedores en muchos sentidos.

** Licenciado en Historia por la Universidad Nacional Andrés Bello; Licenciado en Educación y Profesor en Enseñanza Media con mención en Historia, Geografía y Ciencias Sociales por el Departamento de Estudios Pedagógicos (DEP) de la Universidad de Chile. Actual miembro del Centro de Estudios Sudamérica (CeSud). Correo: javier.sadarangani@gmail.com

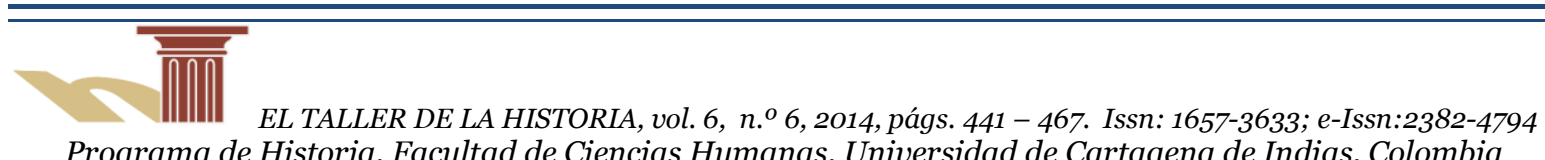

Programa de Historia, Facultad de Ciencias Humanas, Universidad de Cartagena de Indias, Colombia 
responsable de este discurso-, caracterizó de tal forma a una sociedad diversa y heterogénea por definición.

Palabras Claves: Narrativa homogeneizante, nación, historiografía liberal, sociedad chilena.

\title{
Under the quill of nation. The homogenizing narrative of the liberal historiography about Chilean society ca.1810
}

\begin{abstract}
The homogenizing discourse that we notice among the members of the Chilean society doesn't appear spontaneously or fortuitously, but it's a result of a historiographical tradition that's spread and set up in the common sense of many, which understood and described our society on a uniformly way, especially to 1810 . So, the purpose of this article is to expose, through a bibliographic analysis, how and why the liberal historiography -responsible of this discourse-, characterized in that way to a diverse and heterogenic society.
\end{abstract}

Key words: Homogenizing narrative, nation, liberal historiography, Chilean society.

\section{Introducción}

En octubre del año 2006 el periódico El Mercurio publicó los resultados de una encuesta denominada "Encuesta Bicentenario", a propósito del advenimiento de aquella simbólica fecha que conmemoraba los doscientos años de la independencia de Chile. Esta buscaba realizar un sondeo sobre "cómo somos los chilenos. ¿Qué pensamos sobre la identidad y pertenencia a la nación?...”. Se publicó y difundió jactándose de ser altamente confiable, con el fin de "medir, interpretar y divulgar las principales tendencias de la sociedad chilena". ${ }^{1}$ Encuestas, reportajes y notas de esta índole fueron cada vez más frecuentes en medios escritos y visuales ad portas a la fecha en cuestión, buscando dar cuenta sobre la esencia que define a los chilenos.

1 http://goo.gl/9xU3P9. 
Más allá del trato apresurado de ciertos conceptos e ideas, llama profundamente la atención, entre otras cosas, esta tendencia automática de pensar "lo chileno" como una categoría estática y cerrada y como un ente uniforme y homogéneo, en el cual todos los miembros de la sociedad poseen cualidades no similares, sino idénticas. ¿Qué significa "ser chileno"? ¿Quiénes son "los chilenos"? Estas alocuciones se han acentuado y multiplicado durante la última década dada la mencionada reiteración mediática, lo cual ocurre especialmente durante las efemérides nacionales pero más aún a propósito del Bicentenario, haciendo de frases como "la picardía del chileno", "el chileno es flojo" entre otras, de libre circulación discursiva entre la población. ¿Cómo se explica esto? ¿Qué origen tiene este discurso tan arraigado en la sociedad chilena y que nos hace vernos como una sociedad uniforme y estática en el tiempo?

El ejercicio de rastrear los orígenes de la concepción de "lo chileno" no está libre de desencuentros. Mientras los más proclives a los valores nacionales señalan que el surgimiento de una identidad "nacional" que evoque ciertas distinciones respecto a un "otro" tiene su génesis a comienzos del siglo XVI, ${ }^{2}$ creemos por nuestro lado que dicha concepción no podemos identificarla antes de la maduración del descontento hispanoamericano ante las medidas de la casa de Borbón a finales del siglo XVIII, lo cual vendría siendo una suerte de preludio del discurso nacionalliberal concebido desde $1810 .^{3}$ Entonces, para aproximarnos estas interrogantes creemos que debemos comenzar por estudiar algunas características del comportamiento de la nación como artificio histórico. Preliminarmente, diremos que se trata de un discurso altamente legitimador, el cual surge con más intensidad en contextos específicos en los que se alude a esta idea como lo es la conmemoración de los hitos nacionales u otros eventos. ${ }^{4} \mathrm{Si}$ bien la "nación" es un concepto polisémico y que posee bastantes características, una de las más esenciales, a nuestro juicio, ha sido indicada y desarrollada por la autora argentina Mónica Quijada al

2 Sergio Villalobos, Osvaldo Silva, Fernando Silva y Patricio Estellé, Historia de Chile, Santiago, Ed. Universitaria, 2005.

3 John Lynch, Las revoluciones hispanoamericanas 1808-1826, Barcelona, Ariel, 2010, p.35.

4 La frase deja inherente la idea de que el discurso nacional se mantiene casi inerte, pero que se acentúa en estos "otros eventos". Los últimos años han sido testigos de cómo las tragedias naturales o sociales- han evocado este sentimiento. El terremoto el año 2010 y 2014 en el centrosur y norte del país respectivamente; el derrumbe de la mina San José; y el incendio en Valparaíso de 2014 son ejemplos de aquello. 
referirse a la "etnización de las sociedades", ejercicio propio de quienes se inclinan por una acepción historista-romántica de la nación, ${ }^{5}$ es decir la: “... conversión de grupos heterogéneos en una entidad única, que había de ser representada en el pasado y en el futuro como si formase una comunidad natural, en posesión de una identidad de orígenes, cultura e intereses que trascendía a los individuos y a las condiciones sociales" ${ }^{6}$

En otras palabras, se trata de una naturalización de la nación étnica o cultural, la cual le quita su característica de construcción histórica argumentando que esta ha existido desde tiempos prematuros. Esta se enmarca dentro de posturas esencialistas gestadas al calor de la experiencia alemana que, además, concibe a la nación como un fenómeno que es evolutivo y que escapa a toda voluntad humana, dándose un desarrollo natural y coherente en el curso de la historia. Traemos a colación esta cualidad de la nación afirmando que ella, más que otras, genera mayores grados de adhesión y pertenencia a ella por los rasgos de emocionalidad que genera entre quienes permea. De esta forma, busca, por un lado, ubicarse en lo más profundo de la cultura común y por otro, cercenar la posibilidad de pensar a la nación como un producto ficticio cuyos responsables son sujetos reales.

Ahora, la nación en tanto construcción histórica, requiere de un discurso que se propague en orden de seducir al resto de la sociedad expectante, pues éste no emerge en ellos de manera espontánea. Entonces, habría quienes se desempeñan como garantes de ella en términos discursivos, verdaderos intelectuales de la nación: la intelligentsia, que pregonan y difunden sus valores evangelizando a los miembros de la sociedad que no gozan conocer sus verdades. Políticos y profesores; mercaderes y terratenientes; e incluso militares que a su vez han formado parte de una suerte de panteón de héroes insertos en la memoria oficial. Pero, ¿̇qué responsabilidad le cabe al historiador al momento de propagar los fundamentos de la na-

\footnotetext{
5 A la hora de perfilar los rasgos que definen a la nación se reconocen dos dimensiones no excluyentes entre sí: la nación cívica o política, y la nación étnica o cultural, cada una desarrollada por dos experiencias europeas distintas. Mientras el nacionalismo francés se fundamentó en la primera acepción, el caso alemán lo hizo para el segundo. Varios teóricos de la 'nación' han desarrollado estos aspectos llegando a conclusiones diversas, a modo de ejemplo revisar Eric Hobsbawm, Naciones y nacionalismos desde 1780, Barcelona, Editorial Crítica, 1998, pp.23-43.

6 Mónica Quijada, Carmen Bernand y Arnd Schneider, Homogeneidad y nación. Con un estudio de caso: Argentina, siglos XIX y XX, Madrid, CSIC, 2000, p.24.
} 
ción? ¿Es éste el responsable de que nos describamos a nosotros mismos de manera uniforme? Son estas interrogantes las que recorren, soslayadas, las páginas de este trabajo, poniendo especial atención en la continuidad e invariabilidad que han tenido algunos historiadores al caracterizar a la sociedad decimonónica chilena.

\section{1.- El historiador y la nación}

Tanto la consciencia como la memoria histórica propias de una sociedad son fruto de las construcciones discursivas realizadas mayormente por historiadores(as), en tanto el oficio mantenga estrechos vínculos con aparatos hegemónicos. De esta forma, el rol de los(as) historiadores(as) en la producción de dichas concepciones en torno a condiciones políticas, sociales y culturales de nuestra realidad actual es de vital importancia y de directa responsabilidad, lo cual enviste a nuestra labor de una cualidad política y nos obliga a ser responsables y rigurosos en el discurso que, como profesionales de la historia, emitimos. Son las pesquisas propias de nuestra labor las que nos permiten, eventualmente, proyectar imágenes desde la historia hacia el presente y, así, desarrollar ideas en torno a, por ejemplo, nuestra composición socio-cultural. ${ }^{7}$

Sobre la nación, la postura de historiadores e historiadoras ha variado en el curso del tiempo. En cuanto a la situación actual hoy en día es bastante difícil aseverar que exista un número mayoritario de ellos que legitimen las acciones y principios nacionales que toman lugar en nuestro país. Es más, si realizamos un sondeo sobre las posiciones que asumen los exponentes de la historia que han pensado a la nación, sus conclusiones han decantado en una suerte de oprobio público hacia ella, algunos por cierto más enfáticos que otros. Tampoco diremos que abunda la literatura relacionada a la nación, pues son más bien exiguos los casos que la han puesto como materia central de sus investigaciones. Sin embargo, el grueso de ellos se posiciona de manera crítica ante lo que ha sido su responsabilidad, principalmente durante los años de Independencia (momento en el que la nación se mani-

7 En efecto, esta facultad de los historiadores está principalmente sometida bajo los intereses políticos que se disputan a la hora de escribir la historia. 
festó abierta y conscientemente por primera vez). Al respecto Eric Hobsbawm fue bastante categórico, e indicó:

... no puedo por menos de añadir que ningún historiador serio de las naciones y el nacionalismo puede ser un nacionalista político comprometido [...] El nacionalismo requiere creer demasiado en lo que es evidente que no es como se pretende [...]Los historiadores están profesionalmente obligados a no interpretarla mal, o, cuando menos, a esforzarse en no interpretarla mal. ${ }^{8}$

Otros casos más familiarizados con la experiencia chilena han expresado sentires igualmente reprobatorios pero prestando más atención al análisis de los procesos de los cuales nos queremos referir. Por ejemplo, el historiador chileno Jorge Pinto, realizando un balance respecto a lo que significó la construcción nacional para el pueblo mapuche, señaló que su consolidación: “...permitió a nuestros grupos dirigentes traspasar su proyecto a los grupos subalternos, generando un sentimiento de chilenidad, que contrasta dramáticamente con la pobreza a que fueron arrastrados muchos campesinos y mineros que no pudieron beneficiarse de los éxitos de la economía”. ${ }^{9}$ En relación a esto, Gabriel Salazar y Julio Pinto indicaron que el proyecto nacional, amparado por el Estado embrionario, desató presiones diferenciadoras haciendo uso de la violencia en lugar de una opción unificadora y de desarrollo como muchos pudieran presumir. ${ }^{10}$

Por otro lado Paulina Peralta, argumentando que el sentimiento nacional propagado por los ideólogos de la nación, además de constituirse como un elemento esencial de identidad colectiva, también fue "un medio eficaz para esconder las incoherencias que presentaba el sistema político". ${ }^{11}$ Refiriéndose al proceso posterior a la "consolidación de la Independencia", Sergio Grez afirmó que el quiebre

8 E. Hobsbawm, Naciones y nacionalismos, p.20.

9 Jorge Pinto, La construcción del Estado y la nación, y el pueblo mapuche. De la inclusión a la exclusión, Santiago, Colección Idea, 2000, p.99.

10 Gabriel Salazar y Julio Pinto, Historia Contemporánea de Chile. Tomo I, Santiago, Ed. LOM, 1999, pp.130-131.

11 Paulina Peralta, iChile tiene fiesta! El origen del 18 de septiembre. 181O-1837, Santiago, Ed. LOM, 2007, pp.40-41. 
producido durante tal período "agudizó los problemas sociales: hambre, opresión, injusticia”, dando a entender que el proyecto nacional poco había transformado las estructuras coloniales. ${ }^{12}$

Finalmente, y refiriéndose a la historiografía dominante, Leonardo León planteó que:

Uno de los propósitos del relato fue trasladar la mirada desde el mundo de las naciones (étnicas) hacia el mundo de la nación cívica o de ciudadanos, eliminando de esa manera la heterogeneidad cultural y racial para dejar instalado un pasado común en el que se fundía y echaba sus raíces el Estado-nación. ${ }^{13}$

En definitiva, los trabajos que han abordado a la nación de manera central o tangencial han concluido que su aparición en la escena histórica ha depredado a los sujetos históricos de un mismo territorio, enconando desigualdades y atentando contra las culturas que alojan al interior de él.

Sin embargo, las posturas de historiadores e historiadoras recién expuestas, las cuales son expresión de un sentir mayor, son una situación que en la actualidad goza de adhesión y popularidad entre el medio disciplinar. Ahora, si realizamos el mismo sondeo con respecto a la posición que asumieron otros historiadores anteriores, la situación resulta diametralmente opuesta, especialmente aquellos que adscribían a lo que hoy conocemos como la "historiografía liberal".

¿Cuál fue la postura que se inoculó entre los historiadores liberales respecto de la aparición y el desarrollo de la nación? ¿A qué se debió? ¿Cómo se expresó esta postura a la hora de caracterizar a la sociedad chilena en los albores de la patria? Estas preguntas son las que articulan la estructura del presente trabajo y a las cuales buscamos dar respuesta.

12 Sergio Grez, De la regeneración del pueblo a la huelga general. Génesis y evolución del movimiento popular en Chile. 1810-189o, Santiago, RIL Eds., 2007, p.192.

13 Leonardo León, Ni patriotas ni realistas. El bajo pueblo durante la independencia de Chile. 1810-1822, Santiago, DIBAM, 2012, p.79. 


\section{2.- Los perfiles de la voluntad liberal}

El sindicar responsabilidad a una tendencia historiográfica particular sobre el discurso homogeneizante que somos capaces de percibir entre los miembros de nuestra sociedad nos obliga a precisar los elementos que caracterizan a esta forma de construir la historia ¿Qué afinidades muestra respecto al fenómeno de la nación y por qué?

La primera conjetura a establecer es que cuando nos referimos a la historiografía liberal hablamos sencillamente de la historiografía del liberalismo, es decir aquella que se sitúa desde los principios tanto políticos-ideológicos como sociales y económicos que ella profesa, y es desde aquella tribuna que interpreta la historia. Por consecuencia, definir al liberalismo se convierte en una tarea de primer orden.

La ideología liberal se ha venido fraguando en Europa desde mediados del siglo XVII (otros retrotraen su mirada, incluso, hasta el Medioevo) bajo la autoría de pensadores como John Stuart Mill, Adam Smith y John Locke por mencionar algunos, y más tardíamente destacan figuras como Benjamin Constant y Alexis de Tocqueville. Las medidas económicas defendidas por el liberalismo, como la reducción del Estado en asuntos de producción y comercio, y la autorregulación del mercado (la llamada "Mano Invisible") fueron artimañas que tempranamente sedujeron, incluso, hasta los más proteccionistas de algunas de las cortes del viejo mundo, al punto de reorientar sus modelos de desarrollo. En cambio, sus fundamentos políticos tuvieron una acogida desigual, en cuanto podían ser capaces de aceptar sólo algunas de ellas pero difícilmente todas. Si bien no todo liberalismo fue antimonárquico como lo demuestra el caso inglés, el más difundido y ampliamente aceptado tanto en Europa como en América es aquel que se desprende completamente de la figura del monarca, lo cual implicó álgidos conflictos y serias tensiones en el seno de las élites locales. La Revolución francesa de 1789 fue una clara expresión de aquello, la cual demostró de manera explícita dicha tensión y la transición que se dio entre el antiguo y el nuevo régimen. ${ }^{14}$

14 Para mayor profundidad en este punto consultar Iván Jaksic y Eduardo Posada (ed.), Liberalismo y poder. Latinoamérica en el siglo XIX, Santiago, Fondo de Cultura Económica, 2011, p.30 
A partir de entonces, el liberalismo asumió un carácter expansivo, no sólo entre los países europeos, sino que también ingresó en la América hispana. "La literatura de la Ilustración circulaba en Hispanoamérica con relativa libertad", ${ }^{15}$ señaló John Lynch, por lo que no era necesario valerse del mercado ilegal para adquirir dicha bibliografía como se pensó por mucho tiempo. Lo cierto es que en Chile los lectores interesados eran pocos: Manuel de Salas y José Antonio Rojas son ejemplo de aquello, por ende la circulación en esta región era bastante menor que en los virreinatos. ${ }^{16}$ Hacia el período tardo-colonial se dio un proceso de mediación de las ideas liberales pues se mostró como una tendencia novedosa, revolucionaria y especialmente atractiva para quienes ya el sistema colonial les producía cierto escozor. Sin embargo estas ideas nunca se expresaron al punto de buscar una separación con la corona pues las objeciones de los americanos eran más pragmáticas que ideológicas.

Pero años más tarde el panorama mostró un abrupto giro motivado fundamentalmente por los acontecimientos en la península. En Chile, con las proclamas que circularon de manera abierta a partir de 1812 a través de los primeros periódicos (coadyuvados, por supuesto, por la coyuntura), los liberales comenzaron a difundir cada vez más arengas anti-monárquicas y anti-hispanas, las cuales eventualmente constituyeron las bases ideológicas del movimiento "emancipador". Esta expansión no estuvo exenta de diferencias importantes entre distintos sectores sociales de nuestro país, cuyo desenlace final condujo a que el liberalismo se situara, hacia finales del siglo XIX, como hegemónica entre los círculos de poder, copando espacios tan recónditos como la labor historiográfica.

Los historiadores, y casi la globalidad de la intelectualidad criolla, mostraron una prematura adhesión al liberalismo dadas las atractivas respuestas que otorgaba hacia la comprensión de un mundo políticamente convulsionado. Estos historiadores eran efectivamente partidarios del liberalismo, y a partir de la narración histó-

15 J. Lynch, Las revoluciones hispanoamericanas, p.37.

16 Jaime Eyzaguirre, Ideario y ruta de la emancipación chilena, Santiago, Ed. Universitaria, 1975, p.72. 
rica es que le enseñaban al mundo las bondades de éste. Esto se hizo más elocuente cuando comenzaron a escribirse las primeras páginas de la historia nacional. ${ }^{17}$

En primera instancia, la incipiente nación debió mirarse en perspectiva histórica en pos de justificar su existencia, y así empezaron a circular gruesos y pesados tomos, legitimando la presencia de ésta a cargo de los principales precursores del liberalismo en materia historiográfica: el francés Claudio Gay y el chileno Diego Barros Arana. Ambos echaron las raíces de las cuales se cimentaría -más tarde y con mayor fuerza- la tradición liberal al momento de la construcción histórica en conjunto a otros exponentes posteriores. Josefina Zoraida Vásquez, buscando enunciar las características que definen a dicha historiografía, dijo:

... las inquietudes eran políticas y más que el individuo les preocupaba el Estado. Analizaban el parlamentarismo, la gestación de las instituciones liberales, el funcionamiento de la constitución, la estructura de la sociedad y la evolución de las formas de gobierno [...] Buscaban directamente la enseñanza práctica y la prueba a su afirmaciones. La historia era, a la vez, una forma de hacer prosélitos y de aprender política. ${ }^{18}$

Si bien los primeros historiadores en Chile no mantuvieron contacto con aquellos en Europa como François Guizot, Adolfo Thiers y Thomas Babington Macaulay (figuras que la autora describe como exponentes de la historiografía liberal en dicha región), los unía un contexto similar que era la lucha contra el avance del antiguo régimen, al menos desde un frente académico, intelectual y teórico. Eso explica la sintonía que podemos reconocer entre la "pluma nacional" que describe tanto Zoraida como Cristián Gazmuri: "El siglo XIX chileno se caracterizó por producir una historiografía política, militar e institucional de gran nivel pero de hori-

17 La fórmula era simple: la revolución por la independencia y la nación como instrumento político habían otorgado al país la libertad política y económica que el liberalismo tanto ampara; en cambio la Colonia, y todo lo relativo a esta, eran sinónimos de opresión, oscurantismo y retraso. En definitiva, los historiadores ofrecían una perspectiva de la historia situando al liberalismo como "la copia feliz del Edén" de un largo, arduo y oscuro camino que ellos mismos conducían.

18 Josefina Zoraida Vásquez, Historia de la historiografia, México, Editorial Ateneo, 1978, p.120. Una descripción similar se encuentra en Germán Colmenares, Las convenciones contra la cultura. Ensayos sobre la historiografía hispanoamericana del siglo XIX, Bogotá, Tercer Mundo Ed., 1997, p.XXIII. 
zontes aristocráticos, con ocasionales y asistemáticas incursiones en problemas sociales, económicos y culturales”. ${ }^{19}$

Más adelante, el mismo autor, agrega que se trató de una historiografía: "positivista, erudita, narrativa, estrechamente apegada a las fuentes y poco amiga de interpretaciones, aunque implícitamente recogiera inevitablemente simpatías, valores y tendencias ideológicas liberales, antiespañolas y laicas". ${ }^{20}$ En efecto, se trató de una práctica historiográfica que dista mucho de las que se emplean actualmente y que, además, mantuvo intereses diametralmente distintos: "Se trata de una historiografía que privilegia los temas guerreros y militares", y destacó el carácter semipanfletario y de corte nacionalista. ${ }^{21}$

La historia fue (o, más bien, es) otro mecanismo a través del cual la nación y el Estado (expresiones políticas del liberalismo) se validaron ante una sociedad que lentamente dejaba de ser incrédula ante ellos empleando recursos tales como la "etnización social" descrita más arriba. ${ }^{22}$ En ese sentido, la historiadora chilena Florencia Mallon vincula directamente el discurso nacionalista como una manifestación de la idea de hegemonía (en su acepción gramsciana), sosteniendo que ésta puede pensarse como "una serie de procesos sociales, continuamente entrelazados, a través de los cuales se legitima, redefine y disputa el poder y el significado a todos los niveles de la sociedad".23

19 Cristián Gazmuri, La historiografía chilena (1842-1970). Tomo I (1842-1920), Santiago, Centro de Investigaciones Barros Arana, 2006, p.51.

20 C. Gazmuri, La historiografía chilena, p.85.

21 C. Gazmuri, La historiografía chilena, p.85.

22 No obstante, los argumentos desplegados en torno a la validez del liberalismo no debían preocuparse por ser particularmente persuasivos, ya que la anulación de las disidencias políticas, tanto dentro como fuera del patriciado, no se realizaban a través de un intercambio abierto de ideas o principios, sino a través del uso de la fuerza. Las guerras civiles y la represión política fueron expresión de aquello. A modo de ejemplo, ver Gabriel Salazar, Construcción de Estado en Chile (180o1837) Democracia de los "pueblos". Militarismo ciudadano. Golpismo oligárquico, Santiago, Ed. Sudamericana, 2007.

23 Florencia Mallon, Campesino y nación. La construcción de México y Perú poscoloniales, México, CIESAS, 2003, p.85. 
Desde su dimensión política la labor historiográfica según los liberales consistió en validar y enaltecer lo que ellos mismos edificaban: un proyecto nacional que lleve al país al tan anhelado progreso humano. Pero en cuanto a las pesquisas propias de la disciplina ésta debía buscar: "una relación verídica y exacta de acontecimientos ya pasados, y una lección de esperiencia de las cosas y de los hombres de la época en que sucedieron". ${ }^{24}$ Siendo fiel a este principio descrito por Claudio Gay, se propagaron las primeras apreciaciones sobre los hechos, procesos y sujetos de la historia, las cuales poco han variado respecto a la consciencia histórica que se tiene actualmente a nivel social, entre ellas las ideas uniformadoras las cuales, aseveramos, son el sustrato del discurso espontáneo denunciado al inicio de este trabajo.

En consecuencia, la estrechez entre la producción historiográfica y el quehacer político eran inequívocas, pero privilegiando éste último. No es menor el hecho de que estos autores se hiciesen historiadores con la publicación de sus compendios, y no por una formación académica en torno a la disciplina histórica, pues Gay era médico de formación y Barros Arana profesor. Pero sí estuvieron sujetos a onerosos contratos con el gobierno de Chile para la redacción de sus obras e incluso, para el caso de este último, ocupando cargos políticos. Al señalar esto y la uniformidad socio-cultural de la narrativa liberal no ponemos en cuestión la rigurosidad de estas primeras incursiones, pues estaban orientadas hacia un positivismo rankeano que colocaba más preocupación en asuntos políticos que en otras esferas de reflexión. ${ }^{25}$ Queremos enfatizar en una cualidad de estas primeras prácticas historiográficas que es este vínculo señalado al inicio de este párrafo.

Lo cierto es que, a pesar de todo lo descrito anteriormente, la historiografía chilena tiene como sus más notorias figuras fundacionales a sujetos que, no sólo validaron la instalación del Estado-nación sino que (y es lo que nos ocupa en este momento), atentaron discursivamente en contra de la diversidad cultural de la so-

24 Claudio Gay, Historia Física y política de Chile, tomo IV, París, 1844, p.493. Edición digital en http://www.memoriachilena.cl/archivos2/pdfs/MCo019536.pdf

25 Aún así vemos necesario relativizar respecto a la rigurosidad de los autores, pues creemos que son efectivamente rigurosos desde un punto de vista positivista donde sí son capaces de recopilar un número importante de fuentes y documentos a la hora de reconstruir un relato. Sin embargo, este ejercicio de invisibilizar a ciertas colectividades también responde a quitarles el rótulo de "hecho histórico" o "sujeto histórico", lo cual refleja las valoraciones y balances que cada autor hace. 
ciedad chilena del siglo XIX haciendo de ella un conglomerado homogéneo, lo cual profundizaremos más adelante.

La concepción del historiador Sergio Villalobos respecto de la labor de un historiador del siglo XIX como Barros Arana no es muy distinta a la expuesta por Gay, pero sí difiere en cuanto a los juicios valóricos que se le asignan:

No solamente el quehacer práctico y concreto abre cauce al desenvolvimiento de un país, sino también a la orientación dada por los intelectuales desde lo alto. Es muy importante el trabajo material, el esfuerzo corriente de cada día, la aplicación de la técnica, el marco de la ciencia, el cálculo de los profesionales, el aporte de capitales y el discurrir de la política en torno a necesidades y problemas. Pero encima de todo está el espíritu razonador, que partiendo de la experiencia pasada orienta a la sociedad en sus pasos hacia el futuro. Sin el ordenamiento del pensar, las actividades del hombre no serían más que esfuerzos caóticos, contradictorios y nulos generadores de roces y conflictos, que precipitarían a la nación al fracaso. El papel de los intelectuales, entre ellos los historiadores, fue de primer orden en la estructuración de la vida nacional. Fijaron metas y valores a toda la sociedad, marcaron el rumbo de la política, se empeñaron en la educación de la gente de acuerdo a pautas innovadoras, defendieron el país con su saber, hicieron de la prensa una escuela formadora y en sus actuaciones dieron prueba de rectitud y entrega al país. Crearon la conciencia de una nación libre y moderna, segura en su marcha hacia la democracia. Barros Arana fue el mejor ejemplo de esa labor. ${ }^{26}$

Villalobos coincide en reconocer a Barros Arana, entre otros, como uno de los autores intelectuales de la nación, cuyo papel resulta ser gravitante al momento de abrir surcos por donde curse el caudal de la nación. Es incuestionable, por lo demás, la impronta nacionalista desde la cual Villalobos escribe, lo cual sella su texto, al igual que sus mentores, con propósitos de validación política, tanto de la nación misma como de su propio rol.

A continuación queremos exponer los enunciados que nos hemos referido hasta este momento, a través de las cuales estos autores liberales depredan esta diversidad social desde el punto de vista discursivo. Una revisión exhaustiva de la

26 Sergio Villalobos, Barros Arana. Formación intelectual de una nación, Santiago, Ed. Universitaria, 2000, pp.70-71. 
Bajo la pluma de la nación

bibliografía de estos historiadores nos permitirá corroborar si efectivamente asumieron este discurso homogeneizante y qué tan decisivos fueron al respecto.

\section{3.- Un pueblo para una nación}

Hacia 1830 el naturalista francés Claudio Gay se estableció en suelo nacional motivado por un contrato firmado con el incipiente Estado de Chile, en el que se comprometía a recorrer el país con el fin de recolectar los datos y documentos necesarios para elaborar un catastro de las características físicas y biológicas del territorio chileno. No fue sino hasta nueve años más tarde cuando al contrato se le sumó la petición de confeccionar un compendio de la historia política del país. Con la ayuda de sus colaboradores franceses, Gay demoró cinco años más para que el arduo trabajo emprendido se materializara. En 1844 se publicaron los primeros tomos de la Historia física y política de Chile, los trabajos de más antigua data de la historiografía moderna chilena. Esto le valió importantes reconocimientos tanto en Chile como en Francia además de sueldos fabulosos.

Los trabajos de Gay inician su descripción desde tiempos precolombinos y culminan hacia los años treinta del siglo XIX. En la medida que la lectura se aproxima a los "años revolucionarios" las frases se tornan cada vez más ostentosas y acaloradas. No es casual, pues para sus garantes se trata del momento en que la nación rompería finalmente sus cadenas del yugo imperialista. "Así se preparaba una grande revolución en aquella vasta comarca, - menciona el autor -, y ya fermentaba con cierto susurro para desarrollarse, tarde ó temprano, y mostrarse triunfante de preocupaciones y hábitos arraigados, favorecida por grandes acontecimientos que le sirvieron de auxiliares, no de causa esencial". ${ }^{27} \mathrm{Y}$ sentencia: "La revolución de Chile es, sin disputa, la parte la más noble, la más importante y la más gloriosa de su historia, presentándose como emblema del gran movimiento social que ha sacado al país de sus pañales, y le ha hecho crecer de repente, comu-

27 Claudio Gay, Historia Física y política de Chile, tomo v, París, 1849, p.26. Edición digital en http://www.memoriachilena.cl/archivos2/pdfs/mco019519.pdf 
nicándole bastante fuerza para conquistar su nacionalidad, que el egoísmo le había negado hasta entonces". ${ }^{28}$

Más allá de las ucronías presentes, se expresan también conjeturas apresuradas, las cuales son motivadas por fervientes muestras de adhesión nacionalista que conciben estos procesos de manera teleológica y predeterminada, características propias del relato nacional. Esta obliteración analítica hace que se piensen desde categorías absolutas de pensamiento; es más, estas explican de cierta forma las perspectivas homogeneizantes que se manifiestan más adelante:

A la gloria de la conquista mas portentosa de cuantas se leen en historia alguna, glória á la cual seria inútil buscar un parangon, los Chilenos han añadido la de la perseverancia más heróica en formar solo una grande y noble nacion, solos, luchando contra resistencias internas y contra envidias estrañas; luchando contra los hombres y contra los elementos, sin haber desmayado nunca, y la civilización, el mundo entero, y el cristianismo les deben gracias y alabanzas, que, á la verdad, la civilización y la relijion mismas, lejos de negárselas, les tributan alta y universalmente. ${ }^{29}$

Desde la perspectiva de Gay se perfila una tendencia homogeneizante a la hora de comprender colectividades de mayor escala. Las "luchas contra resistencias internas" denotan de manera evidente la pretensión uniformadora que se percibe en el relato historiográfico de Gay. Esta nación avasalladora intimida y arrasa a las "envidias estrañas" que osan disputar su hegemonía dentro del territorio. ¿QQuiénes constituyen estas resistencias internas sino los que no lograron formar parte de un proyecto con exiguos niveles de inclusión como el nacional?

El propósito de establecer una historia política por parte del autor propio del naturalismo de fines del siglo XVIII, impide que realice presunciones desde otras dimensiones. Si bien los enunciados no aluden a aspectos directamente sociales como buscamos señalar, sí nos advierten sobre las lecturas homogeneizantes desde sus análisis políticos e institucionales. Asimismo, nos enseñan que las categorías empleadas por estos autores gozan de un universalismo castrante desde el punto de

28 C. Gay, Historia física y política, tomo V, p.v.

29 C. Gay, Historia física y política, tomo IV, p.498. Negrillas nuestras. 
vista analítico; es decir, "o chilenos o nada", lo cual a la luz del análisis constituye una característica ineludible de la historiografía liberal (y tal vez de otras corrientes y paradigmas). Para el caso de Diego Barros Arana, veremos que es más explícito para nuestros propósitos, pues sí realiza análisis sobre asuntos de orden social.

Los primeros volúmenes de la Historia Jeneral de Chile se publicaron a partir de 1884 teniendo como referencia los trabajos de Gay. Esto le permitió al autor corroborar lo realizado por su antecesor en materias políticas, y a su vez incorporar otras esferas de análisis como lo social, que es lo que nos preocupa. En este aspecto, la postura de Barros Arana es, como ya mencionamos, más explícita, pero no solamente por la naturaleza de las categorías empleadas y que veremos más adelante, las cuales se perciben también desde una óptica social, sino porque es el primer historiador contemporáneo que caracteriza a la sociedad chilena de 1810.

El autor señala que el pueblo de Chile se caracterizaba y diferenciaba de varios otros países latinoamericanos por estar conformado por "una sola raza (mestiza) con una lengua única (el castellano)”. ${ }^{30}$ ¿Qué sucede con la población indígena y negra? ¿Dónde quedan para Barros Arana el mapudungún y el cacán? Ciertamente, no caben dentro de la "comunidad" que "imagina" el autor. Más adelante desarrolla un poco más su mirada, pero arribando a las mismas conclusiones:

La fusion de las dos razas, la conquistadora i la conquistada, se habia operado tan completamente que a fines del siglo XVII, segun contamos en otra parte, todos los pobladores de esta parte del territorio hablaban la lengua castellana, $\mathrm{i}$ pocos años mas tarde habia desaparecido del todo el idioma indígena, o solo se conservaban sus vestigios en los nombres jeográficos, en algunos nombres de personas o en ciertas palabras que se habian hecho de uso comun entre los mismos españoles. ${ }^{31}$

Si bien Barros Arana cifra el ocaso de la diversidad cultural hacia fines del siglo XVII, más adelante indica que este proceso culminó a inicios del 1800. "En Chile, donde al terminarse la dominación colonial se había operado ya la fusión de razas en toda la parte sometida del territorio, de manera que habría sido difícil ha-

30 Diego Barros Arana, Historia Jeneral de Chile, tomo v, Santiago, Ed. Jover, 1887, p.216.

31 D. Barros Arana, Historia Jeneral de Chile, tomo VII, p.448. 
llar al indio puro y sin mezcla, la clase de los mestizos era comparativamente muy numerosa".32

Anteriormente, el autor dedico extensas páginas para "dar luz acerca de la distribución de los habitantes de Chile". En otras palabras, identificar y describir las distintas "razas" que habitaban el territorio durante el período tardo-colonial (blancos, mestizos, indios, negros, etc.), señalando particularidades socioculturales y datos demográficos. Entonces, ¿̇por qué se toma la molestia de realizar este trabajo si su conclusión daría como resultado que en la sociedad chilena ya se había operado la fusión de razas?

La construcción de sociedades uniformes se ha concebido históricamente como una ventaja desde la óptica nacionalista, una ventaja que puede catalizar la materialización de un proyecto colectivo sin tener que lidiar con disidencias políticas. Fueron estos discursos los que fundamentan el que hoy en día se entienda nuestra sociedad como así lo entendieron estos "historiadores". No obstante, no es correcto ni justo atribuir dicha responsabilidad exclusiva a Claudio Gay y a Diego Barros Arana, ya que si bien fueron los precursores de la historiografía liberal en Chile, no fueron sólo los únicos. Vemos posteriormente una camada importante de seguidores liberales (algunos coetáneos y otros bastante posteriores) que mantuvieron el mismo discurso ampuloso de corte nacionalista y que, de cierta manera, fueron los responsables de reforzar ciertas ideas de quienes serían sus mentores. El alcance de las obras de Gay y Barros Arana no tuvo la proyección que tal vez ellos esperaban (al menos inmediatamente), entendiendo que el propósito era construir un sentimiento nacional colectivo. No obstante, sí la tuvo las generaciones venideras. ${ }^{33}$

Posterior a ambos autores encontramos un grupo de historiadores liberales que fijaron su mirada en la Independencia como cuna de la nación que resguardaban; tal fue el ejemplo de los hermanos Domingo y Miguel Luis Amunátegui y el de Benjamín Vicuña Mackenna. Si bien ellos realizaron contribuciones al estudio del

\footnotetext{
32 D. Barros Arana, Historia Jeneral de Chile, tomo viI, p.440.

33 El lento, pero sostenido incremento de los niveles de alfabetización y el incremento en la publicación e importación de libros (principalmente el texto escolar) fueron los motivos que hicieron que el alcance de esta nueva camada tuviera mayor éxito que sus antecesores. Al respecto véase Bernardo Subercaseaux, Historia del libro en Chile, Santiago, LOM Ediciones, 2000.
} 
proceso señalado, al igual que Gay no se detuvieron especialmente en aspectos de índole más social. ${ }^{34}$ No obstante, las lecturas esgrimidas dan cuenta nuevamente del uso de categorías cerradas e, incluso, homogeneizantes desde el análisis político. Miguel Luis Amunátegui, por ejemplo, señaló:

Sin embargo, según lo he dicho al empezar esta disertación, y lo repito ahora, la independencia de la América fue principalmente el resultado de una lucha, no entre los individuos de la raza primitiva y los de la raza extranjera, que, aunque habiendo formado con su mezcla una tercera raza intermedia o mestiza, se habían conservado puras y distintas en porciones muy considerables, sino entre dos divisiones o parcialidades de la raza dominante. ${ }^{35}$

A través de la reflexión de hechos políticos es posible inferir y ampliar cumplimientos acerca de las perspectivas que ofrecen los autores liberales posteriores a Barros Arana.

A partir de entonces, la historiografía propiamente liberal se recluye al interior de los espacios académicos ya habiendo resuelto las implicancias que tuvieron los sucesos ocurridos entre 1810 y 1823 (periodificación tradicional de la Independencia) para la nación chilena, dedicando meditación a otros asuntos. Así, el rol de este proceso en la historia era claro e indiscutible, asimismo las características de la sociedad que protagonizó dichas transformaciones sociales. Ya no habría inquietudes que los llevaran a revisar nuevamente las fuentes. Las relecturas ocurrieron en la medida que una generación de historiadores conservadores aportaban nuevos insumos a la discusión sobre la relevancia y el papel de hechos, procesos y sujetos históricos.

... nacieron las dos grandes líneas de interpretación política de la historia del Chile republicano vigentes, al menos, hasta la década de 1920: la liberal (Barros Arana, Vicuña Mackenna, los Amunátegui) y la conservadora (Sotomayor

34 Nuevamente vemos en ambos autores la tendencia rankeana de afirmar que la escritura de la historia se ciñe a aspectos exclusivamente políticos e institucionales, soslayando elementos que escapen a ella como lo social y lo cultural.

35 Miguel Luis Amunátegui, La Crónica de 181o, tomo I, Santiago, 1876, p.34. Negrillas nuestras. 
Valdés y después Alberto Edwards y Francisco Antonio Encina; en cierta medida Crescente Errázuriz). ${ }^{36}$

Sin embargo, la capacidad interpretativa respecto del análisis social no se agudizó ni afinó con la irrupción de dicha corriente. Ejemplo de aquello es el caso de Francisco Antonio Encina quien, respecto a la problemática que nos convoca, expresó:

Ya atisba la psicología de un pueblo, diferente de la del argentino o del peruano, más todavía en plena ebullición. Sólo en las postrimerías de la Colonia, como si los hombres del momento hubieran querido posar para la posteridad, se delimitan los contornos, hacen un alto los incesantes cambios y se dibujan las formas de una sociedad fácil de aprehender bien representada a través del tiempo. ${ }^{37}$

De la misma forma lo hizo Jorge Edwards quien, sin mayores argumentos, dijo: "Al iniciarse la revolución de la Independencia, el Reino de Chile era de todas las colonias españolas, la de más compacta unidad geográfica y social”. 38

Estos historiadores, al igual que sus “otros" liberales, dibujan una nación unitaria sobre sus habitantes y de su relato nada nos advierte sobre la presencia de una sociedad diversa. Si bien nuestra inquietud se ha posado sobre la pluma de la historiografía liberal aun así vemos los mismos aspectos reprochables en otras corrientes que se han mostrado "contrarias" a ésta. Así, las categorías "liberal” y "conservador" lentamente comienzan a desdibujar sus fronteras y muchas veces se confunden los elementos que los distinguen una de otra.

Ahora bien, la irrupción de nuevas formas escriturales en el campo de la historiografía -como las planteadas por la revista francesa Annales d'histoire économique et sociale, y por otras corrientes como la marxista, inspiradas en el materia-

36 C. Gazmuri, La historiografía chilena, pp.51-52.

37 El destacado nuestro. Francisco Antonio Encina, Resumen de la historia de Chile, Santiago, Ed. Zig-Zag, 1953, p.418.

38 Jorge Edwards, La fronda aristocrática en Chile, Santiago, Ed. del Pacífico, 1928, pp.12-13. 
lismo histórico- sí remecieron a la disciplina en Chile. No obstante, las relecturas respecto del proceso emancipador no fueron significativas, y las perspectivas sobre una sociedad tardo colonial diversa no tuvieron mención alguna. Es más, hispanistas extranjeros como John Lynch y Simon Collier persistieron, ahora de manera abierta, en señalar que la sociedad chilena era homogénea. Así lo expresó el primero de ellos:

Alejada de los grandes focos de la revolución en el subcontinente, la colonia se hallaba bajo la sombra amenazadora del Perú realista, al alcance de las armas y los navíos virreinales. Pero el sentido de identidad de Chile estaba más desarrollado que el del Alto Perú y su clase dominante tenía menos miedo a la revolución. La sociedad era racialmente homogénea. Tenía no más de 800.000 habitantes, alrededor de la mitad de los cuales eran mestizos, con una poderosa elite criolla de terratenientes, comerciantes y propietarios de minas. ${ }^{39}$

Por su parte, Collier sostuvo:

En 1810, Chile era social y geográficamente compacto, cuestión que ayuda a comprender la brevedad del desorden político y la rapidez de la transición a un gobierno bien constituido. Podría decirse también que ningún otro país latinoamericano tenía las ventajas de la unidad geográfica y la homogeneidad social en la misma medida que Chile. ${ }^{40}$

La maduración y el recorrer historiográfico del siglo xx no distinguieron las conclusiones a las cuales arribaron muchos de sus exponentes de aquellas de sus precursores decimonónicos, más bien coadyuvaron al empleo de un lenguaje más específico y grandilocuente altamente validado por sus pares, pero que poco contenido y poco sustento documental trajo. Dicha situación ha sido manifiesta tanto en sus exponentes extranjeros como locales que reproducen las mismas carencias que mostraron sus antecesores.

39 J. Lynch, Las revoluciones hispanoamericanas, p.131.

40 Simon Collier, Ideas y política de la independencia chilena. 1808-1833, Santiago, Fondo de Cultura Económica, 2012, p.40. 
El premio nacional de historia de 1992, Sergio Villalobos es uno de los historiadores que más páginas le ha dedicado a los hechos que se desencadenaron a partir de 1810 y quien más difusión ha tenido de sus posturas en el sentido común. Trabajos como Historia de Chile, Historia del pueblo chileno y Tradición y Reforma en 1810 han sido los libros de cabecera que los maestros escolares ocuparon por mucho tiempo para tratar con sus alumnos el proceso emancipador, lo cual ha hecho de éste historiador y sus inclinaciones aspectos de la historiografía que más amplio impacto han tenido fuera de los círculos académicos.

Dicho autor, junto a Osvaldo Silva, Fernando Silva y Patricio Estellé, en un tradicional compendio de "Historia de Chile", sin mayores argumentos fechan los orígenes de la nacionalidad chilena a fines del siglo XVI una vez que se afianza el asentamiento español, se erige el cabildo como institución comunal y se establece la encomienda como régimen de trabajo. Un origen bastante prematuro en relación a los trabajos que le seguirán, pero coherente a partir del esencialismo al que adscriben y del cual forman parte autores anteriores (Gay, Barros Arana y otros exponentes).

Desde esa perspectiva, la nacionalidad criolla se habría venido fraguando una vez superado el llamado "desastre de Curalaba" y la gesta emancipadora sólo vendría a consagrar e institucionalizar un sentimiento que se cobijaba en el seno de la sociedad chilena con anterioridad a los eventos suscitados a partir de 1810. Respecto de esta última, como si simplemente replicaran los párrafos de otros autores, señalan que en cuanto a los aspectos raciales "tendía a completarse un proceso de homogeneización en que las características físicas se fundían para crear tipos más o menos uniformes en cada estrato". Proceso que se desarrollaba de manera autónoma entre las castas coloniales, es decir tanto en los sectores aristocráticos como en los populares que convivían, incluso, fusionando elementos culturales diversos entre ellos, dándose finalmente un proceso de homogeneización social global. Así, los autores sentencian que:

La existencia de un tipo humano característico no sólo fue el resultado de la intensa mezcla racial, sino también de un proceso cultural y de formas de vida compartidas durante siglos. Tanto blancos, indios y negros aportaron su acervo 
en la plasmación de costumbres, mentalidad y estilos que a través de acciones y reacciones complejas formaron el espíritu distintivo del hombre chileno. ${ }^{41}$

Los autores aseveran que este proceso de homogeneización se dio, como ya lo mencionamos, de manera transversal entre las castas, sin embargo en las páginas posteriores son enfáticos en señalar que dicho fenómeno se acentuó notoriamente entre los sectores populares. "La uniformación racial", señalaron, "en los estratos inferiores y el proceso de disolución de los estamentos, que corren paralelos, estaban dando origen al bajo pueblo chileno, llamado a jugar un papel específico dentro del sistema social". 42

Esta cualidad, entre muchas otras, explica la adhesión que tuvo este sector a la causa emancipadora, según los autores. Este aspecto no es menor pues visibiliza una imagen conciliadora del proceso, arguyendo que el bienestar de la patria fue un asunto de todos y que, específicamente, el bajo pueblo fue protagonista activo a la hora de defender a la nación, tesis que se ha puesto en entredicho últimamente. ${ }^{43}$ Así las perspectivas homogeneizantes no se situarían exclusivamente en una dimensión socio-cultural, sino además a la hora de realizar balances historiográficos, una tendencia reiterativa en el discurso de los autores anteriormente citados.

La idea de un proceso nacional que concernió a todos los sectores sociales fue reproducida por Alfredo Jocelyn-Holt, quien se ha transformado en uno de los historiadores que más atención ha prestado al fenómeno de la nación en Chile y sus impactos. "El nacionalismo es un mecanismo altamente persuasivo del que se sirve el estado liberal-republicano para ofrecer una semblanza de participación popular, en un contexto de limitada participación política real por parte del grueso de la población". ${ }^{4}$

41 S. Villalobos, et. al, Historia de Chile, pp.109 y 257.

42 S. Villalobos, et. al, Historia de Chile, p.255.

43 L. León, Ni patriotas ni realistas.

44 Alfredo Jocelyn-Holt, El peso de la noche. Nuestra frágil fortaleza histórica, Santiago, Ed. Planeta/Ariel, 1999, p.44. 
Si bien el autor se hace eco de ciertos preceptos heredados es importante señalar que sí se desmarca de otras. Cercano a la tradición liberal, a pesar de que constantemente se desmarca de ella, Jocelyn-Holt ya comprende a la nación como producto de la ingeniería social que efectúan las élites a partir de 1810, es decir en tanto construcción histórica y no como resultado natural de la evolución de los pueblos. Aún así reviste al nacionalismo de cualidades inclusivas argumentando que el proyecto invitó a todos a formar parte de la construcción de él, conclusión que difiere completamente de las expuestas por Pinto, Peralta, Salazar y Grez. ¿Cómo explicar la existencia de argumentos tan disímiles unos de otros?

Esto nos evidencia una característica fundamental de la narrativa homogeneizadora, es decir posee una doble acción: iguala hacia el interior, pero diferencia hacia el exterior. El proyecto nacional, más que cualquier otro proyecto histórico fue enfático en definir límites internos dentro del cual operaba la nación. Así, este tendría dos límites claros: los físicos, que comprenden aquellos en donde se ejerce la "soberanía popular"; y los culturales, aquellos que integran a los sujetos "chilenizados". La adscripción de autores como Jocelyn-Holt a una historiografía que ponga atención exclusiva al devenir institucional coarta su posibilidad de analizar lo que ocurre más allá de las fronteras culturales que fijó la nación, esto explica que la conciba inclusiva en lugar de diferenciadora. Aquellos que se ubicaron fuera de estas últimas fronteras fueron los grandes marginados de la historia oficial. Aquellos que estando, no estuvieron; aquellos que fueron igualados a los chilenos, por consecuencia, experimentaron el ocaso de sus culturas originarias.

Este ejercicio homogeneizante llevó a que luego de décadas de tradición historiográfica hoy en día existan historiadores como Jocelyn-Holt que afirmen: "El nacionalismo surgido con la Independencia cumplirá además una serie de funciones. En términos generales, se va a transformar en una herramienta política extraordinariamente útil que va a servir al Estado para integrar y homogeneizar a una sociedad naciente". ${ }^{45}$

¿Fue el nacionalismo efectivamente útil para integrar y homogeneizar a la globalidad de la sociedad? Un análisis superficial de la situación política, social y

45 Alfredo Jocelyn-Holt, La independencia de Chile. Tradición, modernización y mito, Santiago, Mapfre, 1992, p.282. 
cultural actual rápidamente nos daría una respuesta negativa ante la pregunta, haciendo que una de las principales funciones del nacionalismo, en palabras del autor, haya fracasado. Entonces, ¿̇por qué insistir en la efectividad de los mecanismos de homogeneización? La validación del liberalismo historiográfico y la cercanía a la idea de la nación como narrativa hegemónica de las identidades sociales explicarían satisfactoriamente el porqué de las interpretaciones de los autores expuestos. Así se superpone la filiación ideológica más que la rigurosidad disciplinar, opción que muchos tomaron, principalmente quienes asumen una militancia ideológica, ya sea orgánica o no. Tal es el caso de la literatura examinada que muestra con gran elocuencia de qué forma la historiografía se convirtió en la pluma por la cual la nación se fundó, y de qué forma nuestra contemporaneidad nos envuelve irremediablemente sin que podamos marginarnos con facilidad.

\section{Conclusiones}

Ciertamente el exclusionismo no fue concertado únicamente por la historiografía liberal. El propósito de este trabajo ha sido evidenciar uno de los frentes a través de los cuales la visibilización de ciertos sectores se transformó eventualmente en una reivindicación. Hay elementos de naturaleza distinta que coadyuvaron a consagrar este proceso. "Pero no fue tan solo el liberalismo el que estuvo presente en esta construcción exclusionista; también se hizo presente el miedo a la plebe...", ${ }^{46}$ sostuvo Leonardo León. Y más adelante agrega:

En Chile, el relato histórico ahogó las identidades regionales, aplastó el poder de la plebe y elevó a la aristocracia al papel de sujeto predominante y exclusivo en la gesta republicana; lo peor fue que dejó a los patricios convertidos en líderes de un movimiento de liberación nacional, ocultando su verdadera naturaleza de sujetos ávidos de poder, interesados en proteger sus riquezas y privilegios. Al mismo tiempo, dejó a los plebeyos convertidos en una masa amorga, sin conciencia, sumidos en las iniquidades de una cultura subalterna, bárbara, disipada, viciosa y levantisca. ${ }^{47}$

\footnotetext{
46 L. León, Ni patriotas ni realistas, p.76.

47 L. León, Ni patriotas ni realistas, p.77.
} 
Los historiadores nos hemos dedicado a comprender, explicar, analizar los hechos ocurridos en la historia; los ya conocidos y los que aún no conocemos con profundidad. Pero poco nos hemos dedicado a dar cuenta de la responsabilidad política que recae sobre nosotros al momento de enfrentarnos a una hoja en blanco.

La pluma de la nación ha desdibujado los bemoles de las sociedades latinoamericanas cuya definición se basa en su heterogeneidad. Las culturas que habitan al interior de estas sociedades se han silenciado, ennegrecido y eclipsado bajo el discurso aplastante que la nación posaba sobre sus hombros, negándoles sus particularidades y condiciones culturales.

Un análisis de la realidad socio-cultural de hoy nos lleva a descartar la idea que efectivamente exista una homogeneidad social, por lo que su afirmación sólo responde a un anhelo o una percepción discursiva - pues constituye una irrisoria entelequia nacionalista el creer efectivamente en las sociedades homogéneas -, de igual forma esta aspiración ha dejado secuelas en la memoria histórica colectiva y en la auto percepción que hoy en día se construye sobre nuestra sociedad: exclusionismo, racismo, xenofobia, etc. Así, el desmoronar este discurso se convierte en un propósito desde el punto de vista historiográfico como también político, de manera que sea fiel a los hechos históricos. "...se puede interpretar el mundo mientras se intenta cambiarlo", ${ }^{48}$ sostiene la historiadora feminista Joan Wallach Scott. A estas alturas estamos lejos de asumir la inocencia y la apatía política de la labor historiográfica, desde tiempos de Gay que ésta ha tenido inclinaciones claras respecto a la contingencia y a los proyectos históricos que se han sucedido, por consecuencia la noción positivista de la objetividad como un valor y un propósito no pudo ser asumida ni por sus más férreos defensores. Un análisis que incorpore elementos biográficos de los autores pondría en evidencia la vinculación de los historiadores liberales con las instituciones que buscan respaldar, y es natural que así fuese, pero este hecho coartó la rigurosidad que demanda la disciplina, asegurando la existencia de sociedades homogéneas y posicionando a la nación en el cetro de la voluntad colectiva. "Los hechos humanos", sostuvo Marc Bloch, "son esencialmente fenómenos muy delicados y muchos de ellos escapan a la medida matemática. Para tradu-

48 Joan Wallach Scott, Historia y género, México, Fondo de Cultura Económica, 2011, p.24. 
Bajo la pluma de la nación

cirlos bien y, por lo tanto, para comprenderlos bien [...] se necesita gran finura de lenguaje, un color adecuado en el tono verbal" ${ }^{49}$

Negar las diversidades culturales de las sociedades latinoamericanas y establecer, en cambio, su homogeneidad responde a principios esencialistas y, a su vez, reduccionistas propios del discurso nacional que forzosamente aglutina bajo categorías amplias y universales a grupos humanos casi ajenos entre sí. Visibilizar esta tensión constituye sólo un primer paso.

\section{Bibliografía}

Amunátegui, Miguel Luis, La Crónica de 181o, tomo I, Santiago, 1876.

Barros Arana, Diego, Historia Jeneral de Chile, tomos V y VII, Santiago, Ed. Jover, 1887.

Bloch, Marc, Introducción a la historia, México, Fondo de Cultura Económica, 2012.

Collier, Simon, Ideas y política de la independencia chilena. 1808-1833, Santiago, Fondo de Cultura Económica, 2012.

Colmenares, Germán, Las convenciones contra la cultura. Ensayos sobre la historiografía hispanoamericana del siglo XIX, Bogotá, Tercer Mundo, 1997.

Edwards, Jorge, La fronda aristocrática en Chile, Santiago, Editorial del Pacífico, 1928.

Encina, Francisco Antonio, Resumen de la historia de Chile, Santiago, Ed. Zig-zag, 1953.

Eyzaguirre, Jaime, Ideario y ruta de la emancipación chilena, Santiago, Editorial Universitaria, 1975 .

Gay, Claudio, Historia Física y política de Chile, tomos IV y v, París, 1844-1849. Edición digital. $\quad$ http://www.memoriachilena.cl/archivos2/pdfs/mco019519.pdf http://www.youtube.com/watch?v=nvAebBs50TQ.

Gazmuri, Cristián, La historiografía chilena (1842-1970), tomo I (1842-1920), Santiago, Centro de Investigaciones Barros Arana, 2006.

Grez, Sergio, De la regeneración del pueblo a la huelga general. Génesis y evolución del movimiento popular en Chile. 1810-189o, Santiago, RIL Eds., 2007.

49 Marc Bloch, Introducción a la historia, México, Fondo de Cultura Económica, 2012, p.30. 
Hobsbawm, Eric, Naciones y nacionalismos desde 178o, Barcelona, Editorial Crítica, 1998.

Jaksic, Iván y Posada, Eduardo, Liberalismo y poder. Latinoamérica en el siglo XIX, Santiago, Fondo de Cultura Económica, 2011.

Jocelyn-Holt, Alfredo, El peso de la noche. Nuestra frágil fortaleza histórica, Santiago, Ed. Planeta/Ariel, 1999.

Jocelyn-Holt, Alfredo, La independencia de Chile. Tradición, modernización y mito, Santiago, Mapfre, 1992.

León, Leonardo, Ni patriotas ni realistas. El bajo pueblo durante la independencia de Chile. 1810-1822, Santiago, DIBAM, 2012.

Lynch, John, Las revoluciones hispanoamericanas 18o8-1826, Barcelona, Ariel, 2010.

Mallon, Florencia, Campesino y nación. La construcción de México y Perú poscoloniales, Ciudad de México, CIESAS, 2003.

Peralta, Paulina, iChile tiene fiesta! El origen del 18 de septiembre. 1810-1837, Santiago, Ed. LOM, 2007.

Pinto, Jorge, La construcción del Estado y la nación, y el pueblo mapuche. De la inclusión a la exclusión, Santiago, Colección Idea, 2000.

Quijada, Monica et. al., Homogeneidad y nación. Con un estudio de caso: Argentina, siglos XIX y XX, Madrid, Editorial CSIC, 2000.

Salazar, Gabriel, Construcción de Estado en Chile (180o-1837) Democracia de los "pueblos”. Militarismo ciudadano. Golpismo oligárquico, Santiago, Editorial Sudamericana, 2007.

Salazar, Gabriel y Pinto, Julio, Historia Contemporánea de Chile. Tomo I: Estado, legitimidad, ciudadanía, Santiago, Ed. LOM, 1999.

Subercaseaux, Bernardo, Historia del libro en Chile, Santiago, Ed. LOM, 2000.

Vásquez, Josefina Zoraida, Historia de la historiografía, México, Editorial Ateneo, 1978.

Villalobos, Sergio, Barros Arana. Formación intelectual de una nación, Santiago, Editorial Universitaria, 2000.

Villalobos, Sergio et. al., Historia de Chile, Santiago, Editorial Universitaria, 2005.

Wallach Scott, Joan, Historia y género, México, Fondo de Cultura Económica, 2011. 